\title{
Fracture Behavior of Granular Polycrystalline Silicon Using Micro-scale and Macro-scale Indentation Techniques
}

\begin{abstract}
MOHAMAD B. ZBIB and DAVID F. BAHR
Three batches of polycrystalline silicon (polysilicon) produced with the fluidized bed reactor method were used to study the fracture behavior using micro-scale and macro-scale indentation techniques. The fracture toughness was determined to be $0.60,0.74$, and $0.86 \mathrm{MPa} \mathrm{m}{ }^{0.5}$ using Vickers microhardness tests for three samples with a high, medium, and low hydrogen content, respectively. In the same order of the samples, Rockwell hardness tests showed that they failed at applied loads of 45,55 , and $60 \mathrm{~kg}$, respectively. These results show that the fracture behaviors of both techniques are in agreement; the highest toughness materials can withstand higher loads prior to fracture in the Rockwell hardness test. The microstructure of the granular product has been documented and the only significant difference between the samples is the solute hydrogen content. Therefore, a Rockwell hardness instrument can be used as a rapid way to assess the relative fracture toughness of the as-grown polysilicon for solar applications, and the technique is insensitive to small amounts of porosity in these materials.
\end{abstract}

DOI: $10.1007 / \mathrm{s} 40553-013-0002-5$

(C) The Minerals, Metals \& Materials Society and ASM International 2013

\section{INTRODUCTION}

POLYCRYSTALLINE silicon (polysilicon) produced using the fluidized bed reactor (FBR) method is mainly used in solar cell applications and the production of single crystal silicon. Granules (mm's size) and nanopowders (10 to $100 \mathrm{~nm}$ in diameter $)^{[1]}$ of polysilicon are produced from the FBR process using chemical vapor deposition (CVD) of silane $\left(\mathrm{SiH}_{4}\right)$ at temperatures between $923 \mathrm{~K}$ and $1023 \mathrm{~K}\left(650{ }^{\circ} \mathrm{C}\right.$ and $\left.750{ }^{\circ} \mathrm{C}\right)$, or trichlorosilane $\left(\mathrm{SiHCl}_{3}\right)$ at temperatures between $1223 \mathrm{~K}$ and $1323 \mathrm{~K}\left(950{ }^{\circ} \mathrm{C}\right.$ and $1050{ }^{\circ} \mathrm{C}$ ), in a hydrogen-rich environment. The produced polisilicon has grain sizes in the $10 \mathrm{~s}$ of nm regime. ${ }^{[2]}$

Bead fracture during handling is a problem in processing this material for subsequent solar cell growth because dust can result from grinding while shipping the material in large quantities, which can be hazardous to subsequent users and handling. Most of the fracture behavior studies that have been done on polysilion use nanoindentation, microindentation, or four point and cantilever beam techniques. Our previous work has determined that the fracture toughness of the as-grown FBR polysilicon ranges between 0.6 and $0.97 \mathrm{MPa} \mathrm{m}{ }^{0.5}$, using Vickers microhardness tests and nanoindentation tests. ${ }^{[1,3]}$ These values will be compared to the new data presented in this paper using the same techniques, and compared to a new macro-scale technique for assessing fracture behavior. Other polysilicon produced from the Siemens process has toughness values of $\sim 0.8 \mathrm{MPa} \mathrm{m}{ }^{0.5[4]}$ for the as-grown materials. Other research groups have determined the

MOHAMAD B. ZBIB, Ph.D. Student, and DAVID F. BAHR, Professor and Head, are with the School of Materials Engineering, Purdue University, West Lafayette, IN 47907. Contact e-mail: dfbahr@purdue.edu

Manuscript submitted June 19, 2013.

Article published online December 18, 2013 fracture toughness of polysilicon to range between 0.6 and $0.95 \mathrm{MPa} \mathrm{m}{ }^{0.5} \cdot{ }^{[5-11]}$ In general, it is reasonable to assume that the toughness of the as-grown polysilicon is on the order of $1 \mathrm{MPa} \mathrm{m}{ }^{0.5}$.

Studying the mechanical properties using impact or compression tests for brittle materials has not been used as much as the indentation techniques. Different types of single-particle tests (crushing tests and impact tests) have been done to investigate the breakage of other hard particle materials and to analyze the distribution of fracture energy under controlled loading conditions. ${ }^{[12]}$ A study has been done to study the milling behavior of crystalline organic substances using single-particle impact tests and compared them to the material properties from indentation techniques; those results showed that there is a relationship between indentation and bulk milling behavior, where the resistance of particulate material against fracture and the absorption energy are related to a brittleness index (ratio of hardness to fracture toughness). ${ }^{[13]}$ Another research group has developed a theoretical and experimental model of impact attrition of particulate solids for semibrittle failure mode which provide an identification of impact mechanical properties; they defined a dimensionless attrition propensity parameter, $\eta$, that is related to impact conditions and material properties. ${ }^{[14,15]}$ The parameter is

$$
\eta=\frac{\rho v^{2} l H}{K_{\mathrm{c}}^{2}},
$$

where $K_{\mathrm{c}}$ is the fracture toughness, $H$ is the hardness, $l$ is a characteristic particle size, $v$ is the impact velocity, and $\rho$ is the particle density.

Assessing the fracture behavior of polysilicon can be challenging according to the techniques used, and their associated sample preparation, handling, and testing. 
The purpose of this paper is to develop a new method to have a rapid assessment of fracture behavior of polysilicon fabricated for the solar industry using a Rockwell hardness test to do a single-particle test. This work will compare the fracture behavior of polysilicon using micro-scale technique (Vickers microhardness test) and macro-scale technique (Rockwell hardness test).

\section{EXPERIMENT}

Three batches of polysilicon were examined in this study; all of them were produced from the same manufacturer (REC Silicon Inc.), but with modest proprietary changes in hydrogen concentrations and temperatures during their production. We will refer to these batches as samples 1,2 , and 3 with decreasing $\mathrm{H}_{2}$ during growth, respectively. All these materials are silane-based feedstock materials grown via CVD at temperatures greater than $923 \mathrm{~K}\left(650^{\circ} \mathrm{C}\right)$. All experiments were done for the as-grown granular polysilicon samples that are shown in Figure 1. The samples were selected randomly from growth batches; all sample diameters ranged between 1 and $3 \mathrm{~mm}$. The micromechanical properties (Vickers and nanoindentation) were measured on $\sim 45$ samples for each batch in order to study their fracture behavior and relate this to their morphologies.

The fracture behavior was determined using a Vickers microhardness test, where loads between 0.49 and $4.9 \mathrm{~N}$ were applied, and the sizes of the cracks were measured using an optical microscope. The toughness of the material was then determined by the relationship between the applied load and the crack size. ${ }^{[16]}$

The hardness and elastic modulus were measured using a Hysitron Triboindenter 900, where a quasistatic

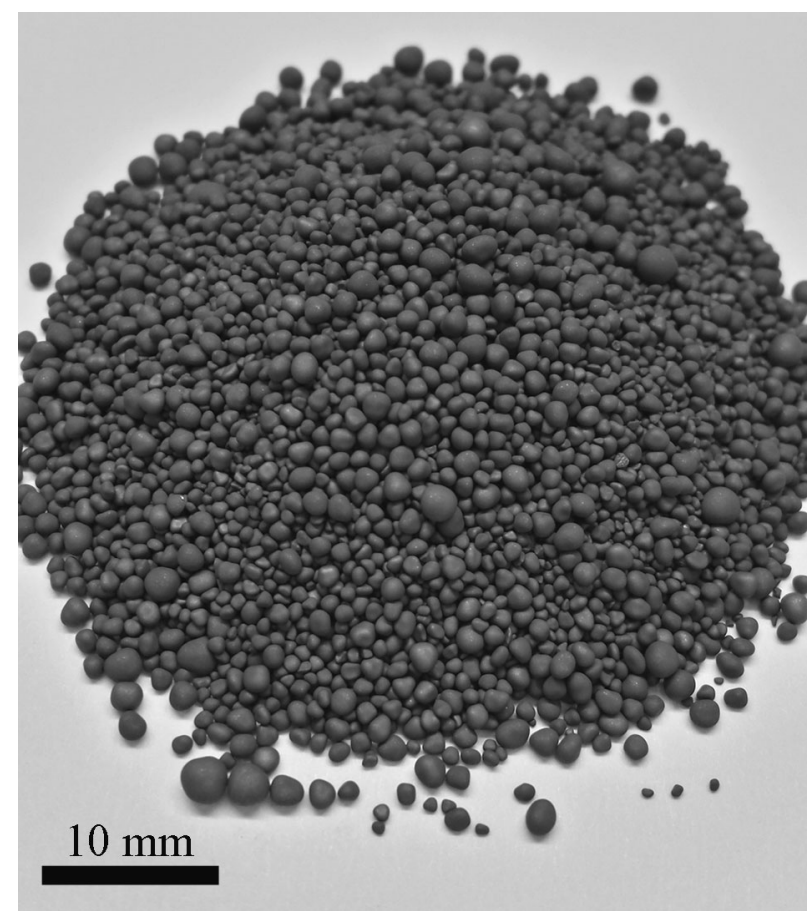

Fig. 1-As-grown FBR granular polysilicon (1 to $3 \mathrm{~mm}$ in diameter). test was performed with maximum applied loads between 1800 and $9000 \mu \mathrm{N}$. In order to avoid any influence on the properties of the materials, all measurements were done at areas much smaller than the pore spacing in the granular material. Hardness and modulus were calculated using the Oliver and Pharr ${ }^{[17]}$ method where they account for the curvature during unloading and the contact area at the peak load by determining the depth that is related to the indenter shape function. Preparation of specimens for measuring the mechanical properties was done using conventional grinding and polishing methods. Representative granular samples were mounted in epoxy, and ground with 240 to 1200 grit silicon carbide abrasive paper. They were then polished using diamond paste from 3 to $0.25 \mu \mathrm{m}$. Note that these sample preparation methods are done only for Vickers and nanoindentation techniques, while macro-indentation tests were done with no prior sample preparation.

The impurities of hydrogen in silicon were identified using a Bomem DA8 Fourier transform infrared (FTIR) spectroscopy with a $\mathrm{KBr}$ (potassium bromide) beam splitter. The granular FBR Si was ground with a mortar and pestle and mixed with $\mathrm{KBr}$ powder, then pressed into pellets of $0.3 \mathrm{~mm}$ diameter. A liquid-nitrogencooled mercury cadmium telluride detector was used at a resolution of $4 \mathrm{~cm}^{-1}$ and spectral range of 400 to $5000 \mathrm{~cm}^{-1}$ wavenumbers.

A commercial Rockwell hardness tester (Wilson 3JR) was used to study bulk fracture behavior on the granular polysilicon of the three batches. An indent, with the size of the granular material, was made on an aluminum tray with circular impressions on the order of the granule size. The granular Si particles were then placed in these impressions prior to indentation. Rockwell tests were performed using a standard "B" steel spherical tip on individual granular polysilicon particles by applying loads between 15 and $75 \mathrm{~kg}$ with no prior sample preparation; the individual granule is tested as a whole sample, and not as a cross-sectioned sample. Approximately 35 samples were selected at random from each batch of the material; the nominal granule diameter was noted for each sample (all samples tested were close to spherical morphology, as are the vast majority of the product as noted in Figure 1).

A Siemens D-500 X-ray powder diffractometer was used to measure the crystallite sizes of the granular material. Granules of polysilicon were ground to a fine powder and samples were prepared on small glass plate with few drops of ethanol. Diffractograms were obtained within the range of $2 \theta=20^{\circ}$ to $65^{\circ}$, with a step of $0.02^{\circ}$ and dwell of 1.0 second. The program MDI Jade 8 was used to perform the data analysis, and the crystallite sizes were determined using the method described by the Williamson and Hall ${ }^{[18]}$ equation:

$$
B \cos \theta=\frac{k \lambda}{D}+\alpha \sin \theta,
$$

where $B$ is the peak width difference, $k$ is a constant $(\sim 1)$, $\lambda$ is the $\mathrm{X}$-ray wavelength, $D$ is the average grain size, and $\alpha$ is the strain. Optical microscopy and a scanning 
electron microscope (SEM) operated at $20 \mathrm{kV}$ were used to study the microstructure of the samples.

\section{RESULTS}

The hardness and elastic modulus of the three different batches of polysilicon did not show very significant changes; they ranged between 9.7 to 11.3 and 145 to $164 \mathrm{GPa}$, respectively. These hardness and modulus values are considered reasonable for sampleto-sample comparison within this study. The elastic modulus was calculated using the Oliver and Pharr ${ }^{[17]}$ method:

$$
\frac{1}{E_{\mathrm{R}}}=\frac{1-v_{\mathrm{i}}^{2}}{E_{\mathrm{i}}}+\frac{1-v_{\mathrm{s}}^{2}}{E_{\mathrm{s}}},
$$

where $E_{\mathrm{R}}$ is the reduced modulus of the unloading slope, $E_{\mathrm{s}}$ is the elastic modulus of the sample, $E_{\mathrm{i}}$ is the modulus of the diamond indenter tip that is equal to $1249 \mathrm{GPa}, v_{\mathrm{s}}$ and $v_{\mathrm{i}}$ are the Poisson's ratio of the sample (0.27) and the diamond indenter tip (0.07), respectively. $E_{\mathrm{r}}$ is related to the stiffness $(S)$ and the known projected area function $(A)$ of the elastic contact by

$$
S=\frac{2}{\sqrt{\pi}} E_{\mathrm{r}} \sqrt{A}
$$

while the hardness $(H)$ is related to the peak indentation load $\left(P_{\max }\right)$ and was calculated using

$$
H=\frac{P_{\max }}{A}
$$

The fracture toughness $(T)$ was determined by

$$
T=\frac{\chi_{\mathrm{r}} P}{c^{3 / 2}}
$$

where $P$ is the applied load using a Vickers microhardness tester, $c$ is the average crack length (Figure 2(a)), and $\chi_{\mathrm{r}}$ is a constant dependent on the specific indenter-material system:

$$
\chi_{\mathrm{r}}=\xi \sqrt{\frac{E}{H}}
$$

where $H$ is the measured hardness, $E$ is the measured elastic modulus, and $\xi$ is the indenter invariant constant which is equal to 0.016 for Vickers tip experiments. ${ }^{[16]}$ In our measurements we use toughness $T$ rather than using mode I fracture toughness $K_{\text {IC }}$ because of the absence of pre-cracks and the indistinct use of indentation-induced fracture. Figure 2(b) shows the average crack vs applied load where Eq. [6] was curve-fitted for each sample to determine $T$. The toughness behaviors that are shown in Figure 2(b) are fitted to $2 / 3$ power relationship according to Eq. [6]. Deviations at low loads are likely due to some inhomogeneity of the product and the difficulty in assessing the crack distances at the shallowest loads used in the study. Table I uses the best fit assuming a $2 / 3$ power. As noted in Figure 2(b) there can be a significant variation among the samples. Note that in Figure 2(a) the cracks do not show any deviation effects from the pores; the variation in properties may be due to variations in grain size or sub-surface texture.

The results showed that the fracture toughness ranges between 0.60 and $0.86 \mathrm{MPa} \mathrm{m}{ }^{0.5}$ for polysilicon with the highest hydrogen content (sample 1) and the lowest hydrogen content, respectively (sample 3); all mechanical properties for all tested samples are listed in Table I. The change in toughness between the three batches is related to the amount of hydrogen in the production process, as mentioned in our earlier studies, where less solute hydrogen leads to higher toughness. ${ }^{[1,3]}$ In these prior studies, it was shown that the hydrogen peak heights in FTIR spectrum are proportional to the amount of solute hydrogen present in the sample. Figure 3 shows the FTIR spectrum, with the background subtracted, for wavenumbers between 1800 and

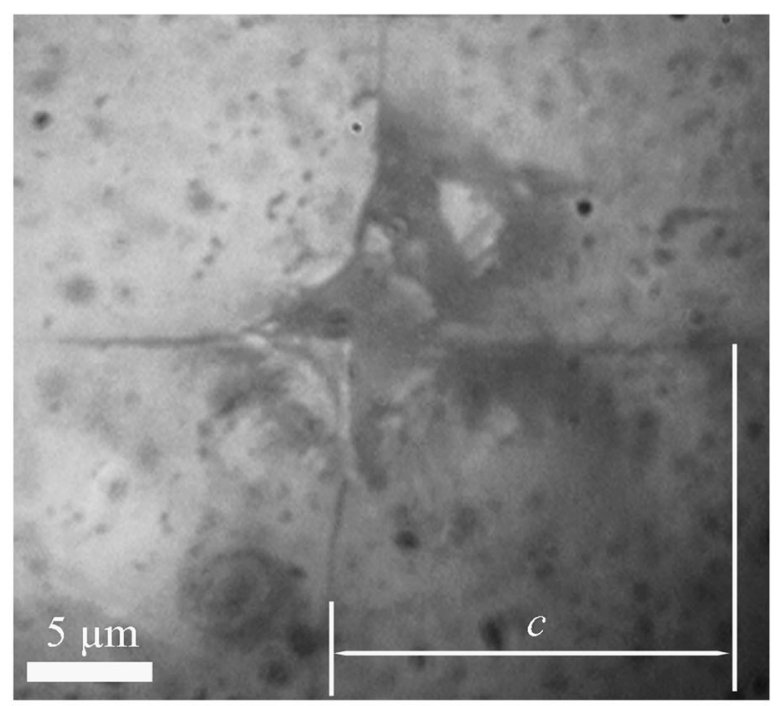

(a)

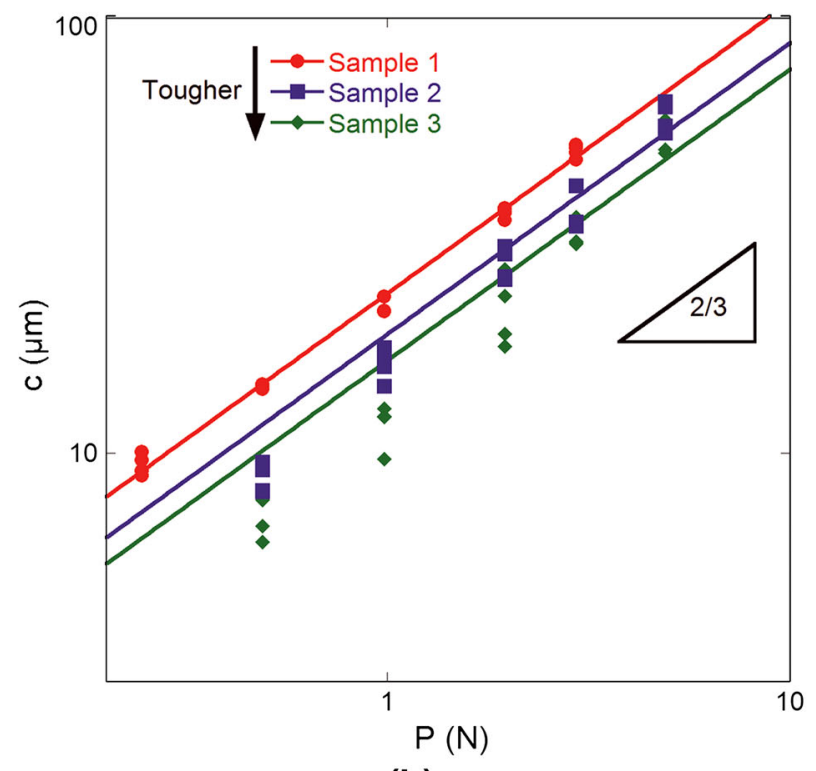

(b)

Fig. 2-(a) Cracks formed around Vickers indentation and (b) average crack size $v s$ applied loads for all polysilicon materials. 
Table I. Mechanical Properties and Crystallite Sizes of all Tested Polysilicon Materials Measured Using Indentation Techniques and XRD, Respectively; About 45 Tests were Performed for Each Batch to Calculate the Average Values and Standard Deviations

\begin{tabular}{lccccc}
\hline Sample & Hardness $(\mathrm{GPa})$ & Modulus $(\mathrm{GPa})$ & Toughness $\left(\mathrm{MPa} \mathrm{m}^{0.5}\right)$ & Crystallite Sizes (nm) & Relative Hydrogen Peak Height \\
\hline 1 & $9.7 \pm 0.4$ & $164 \pm 3$ & $0.60 \pm 0.05$ & $30.0 \pm 2.0$ & 1 \\
2 & $11.2 \pm 0.7$ & $157 \pm 6$ & $0.74 \pm 0.03$ & $30.0 \pm 1.7$ & 0.7 \\
3 & $11.3 \pm 0.8$ & $145 \pm 5$ & $0.86 \pm 0.03$ & $31.3 \pm 1.5$ & 0.1 \\
\hline
\end{tabular}

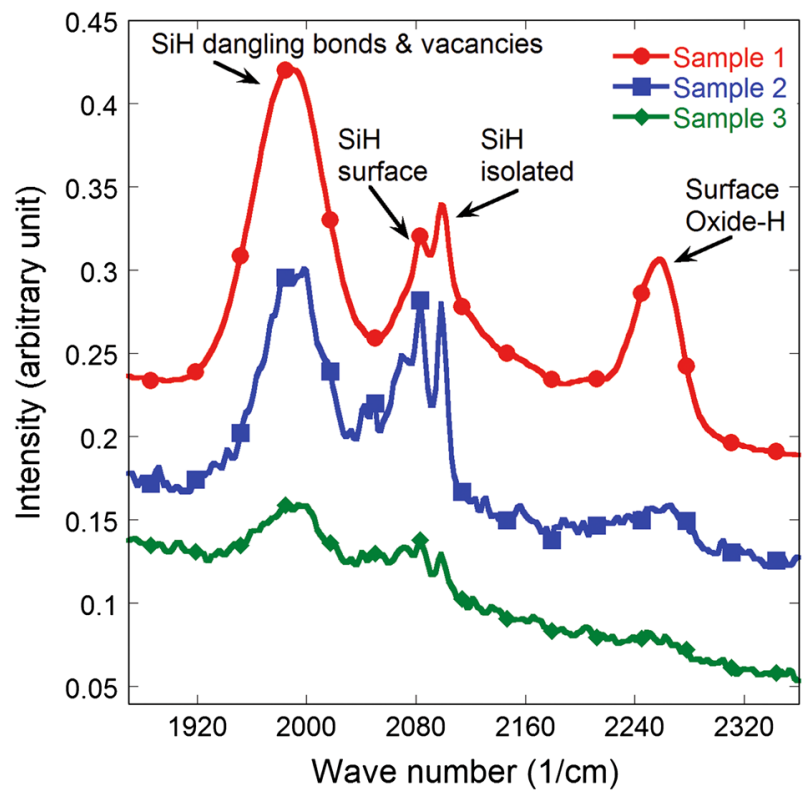

Fig. 3-FTIR spectrum that shows hydrogen defects in silicon.

$2400 \mathrm{~cm}^{-1}$. The relative hydrogen peak heights are normalized by sample 1 with the highest hydrogen content, normalized hydrogen contents are 0.7 for sample 2 and 0.1 for sample 3 (the lowest hydrogen content); these values are reported in Table I. The FTIR spectrum corresponds to hydrogen defects in $\mathrm{Si}$, where four types of bonding occur. Si-H dangling bonds and vacancies have the highest concentration, and other types being less concentrated as $\mathrm{Si}-\mathrm{H}$ bonds on the surface, isolated $\mathrm{Si}-\mathrm{H}$, and $\mathrm{Si}-\mathrm{O}-\mathrm{H}$ present on free surfaces. Other peaks of Si bonding that are not in 1800 to $2400 \mathrm{~cm}^{-1}$ range were identified to be $\mathrm{Si}-\mathrm{Si}$ bonds or contamination of $\mathrm{H}_{2} \mathrm{O}$ with $\mathrm{Si}^{[3]}$

Peak broadening during X-ray diffraction was used to determine the crystallite sizes of polysilicon, and these values are listed in Table I. The three batches have the same crystallite size; thus, this structural feature should have no impact on the change in fracture toughness in this current study.

For Rockwell hardness tests about 35 random tests were performed for each batch to have a rapid assessment of the fracture behavior on the granular polysilicon. Rockwell failure load (RFL) was determined for each sample as the granule starts to fail at an applied load. This was done by visually examining all the samples at different applied loads, ranging from 15 to $75 \mathrm{~kg}$. Granular polysilicon with the lowest toughness (sample 1) failed at applied loads of 30 to $45 \mathrm{~kg}$, the one with medium toughness (sample 2) failed at 45 to $55 \mathrm{~kg}$, and
Table II. Minimum Rockwell Failure Load for Tested Samples at Certain Range of Granular Diameter

\begin{tabular}{lccc}
\hline & \multicolumn{3}{c}{ Rockwell Failure Load (kg) } \\
\cline { 2 - 4 } Granular Diameter (mm) & Sample 1 & Sample 2 & Sample 3 \\
\hline 1.8 to 1.9 & 30 & 45 & 55 \\
2.0 to 2.5 & 45 & 55 & 60 \\
\hline
\end{tabular}

the one with the highest toughness failed at 55 to $60 \mathrm{~kg}$. Rockwell hardness results and Vickers indentation results match with each other regarding the fracture behavior of the three polysilicon batches. Granular polysilicon with an average diameter of 1.8 to $1.9 \mathrm{~mm}$ failed at lower loads than the ones with an average diameter of 2.0 to $2.5 \mathrm{~mm}$. All Rockwell test results are summarized in Table II. Within a given batch the failure on all tested beads occurred in the range reported; there was no evidence of failure in a small number of beads at a lower load (or a higher load).

Figure 4 shows optical images of different crack and failure morphologies at specific applied loads using the Rockwell test. A small crack is initiated on sample 3 when $30 \mathrm{~kg}$ load is applied (Figure 4(a)), a bigger crack is elongated when the load is increased to $45 \mathrm{~kg}$ (Figure 4(b)), and it finally breaks the particle when a $60 \mathrm{~kg}$ load is applied (Figure 4(c)). For sample 2, which is less tough, the granule fractured at an applied load of $55 \mathrm{~kg}$ (Figure 4(d)), while the least tough material failed at $45 \mathrm{~kg}$ (Figure 4(e)) and extensively shattered, as in Figure 4(f); the granular polysilicon shown in Figures 4(a) through (f) are in the size range of 2.0 to $2.5 \mathrm{~mm}$ in diameter.

Figure 5 shows the most common fracture behavior that was observed on the different batches when applying a Rockwell test. All samples show a certain path of crack propagation at applied load of $15 \mathrm{~kg}$, where it elongates more while unloading; Samples 1 and 2 break during unloading at $30 \mathrm{~kg}$, while sample 3 has an elongation in the crack. At $45 \mathrm{~kg}$ sample 1 breaks during loading, and shatters during unloading, while sample 2 breaks during unloading only. Sample 1 cannot withstand more than $45 \mathrm{~kg}$ load without significant fragmentation, while sample 2 fails at $55 \mathrm{~kg}$ and fragments at $60 \mathrm{~kg}$, and sample 3 fails at $60 \mathrm{~kg}$ and fragments at $75 \mathrm{~kg}$.

In order to express the relationship between the Rockwell hardness test procedure and the toughness values, an approach has been identified similar to that of Ghadiri and Zhang ${ }^{[14,15]}$, where they have the attrition parameter identified as in Eq. [1]. However, in this case the modified dimensionless attrition propensity parameter $((\dot{\eta}))$ depends only on the diameter of the granular 


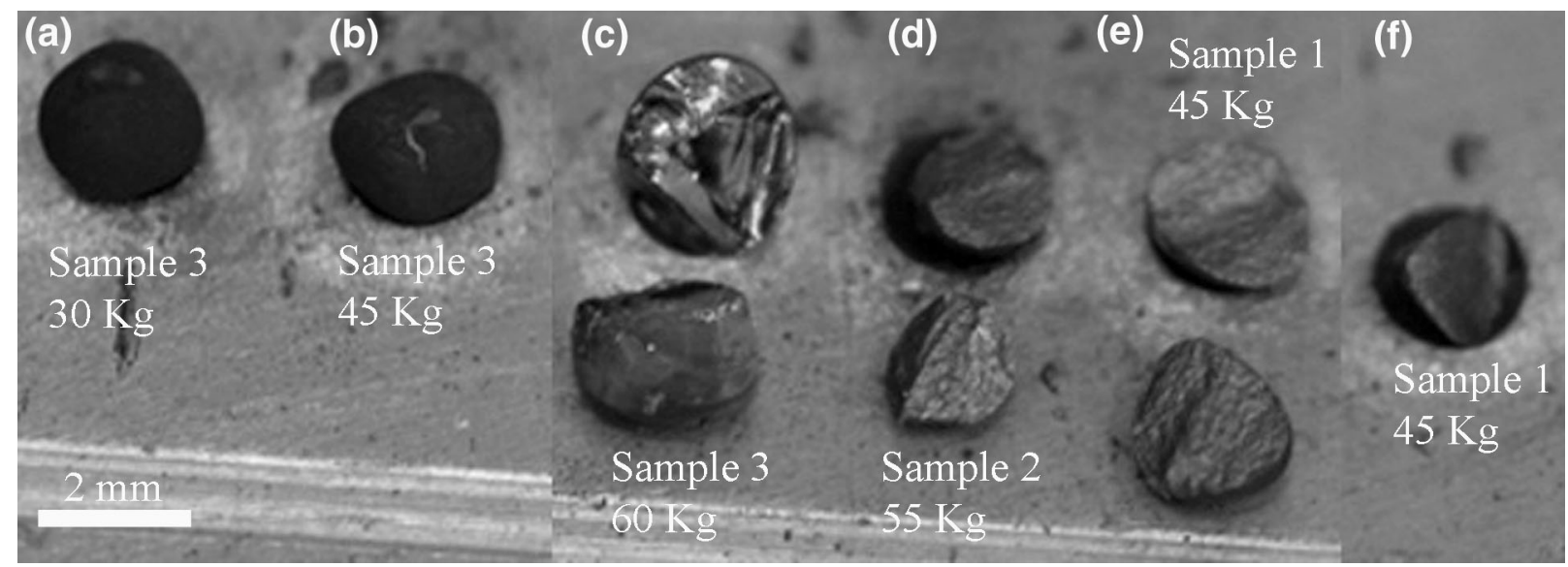

Fig. 4 - Optical images showing Rockwell test, where sample 3 only shows some cracks at 30 and $45 \mathrm{~kg}(a$ and $b)$ and breaks at $60 \mathrm{~kg}(c)$, sample 2 breaks at $55 \mathrm{~kg}(d)$, and sample 1 beaks at $45 \mathrm{~kg}(e$ and $f)$.

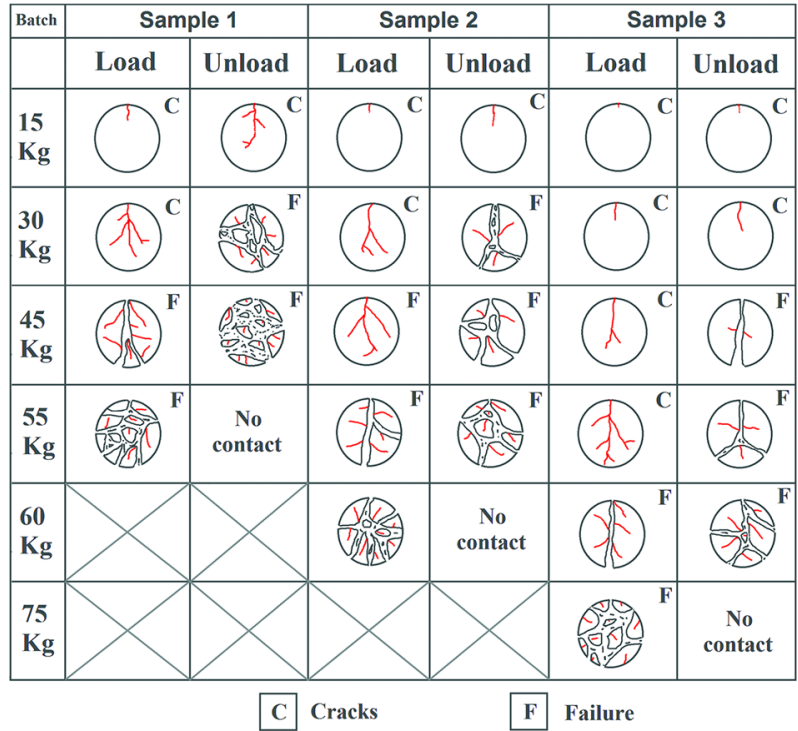

Fig. 5-Schematic drawing showing the fracture behavior of granular polysilicon using Rockwell test.

polysilicon $(l)$, the measured hardness $(H)$, and the fracture toughness calculated above $(T)$. This parameter is defined as

$$
\dot{\eta}=\frac{l H^{2}}{T^{2}}
$$

Figure 6 shows the RFL vs the attrition propensity parameter for the three samples at three different granular sizes. Polysilicon with a lower toughness has a higher attrition parameter, and smaller sized granular $\mathrm{Si}$ shows lower attrition parameter (as would be expected from ${ }^{[13,14]}$ ).

Another way to show the relationship between toughness measurements and RFL is shown in Figure 7, where a linear relationship is expressed by plotting $T v S$ $R F L / l^{2}$. This is shown over a range of granular diameter sizes between 1.8 and $2.5 \mathrm{~mm}$.

SEM was used to study the microstructural behavior of granular polysilicon. The cross section of polysilicon

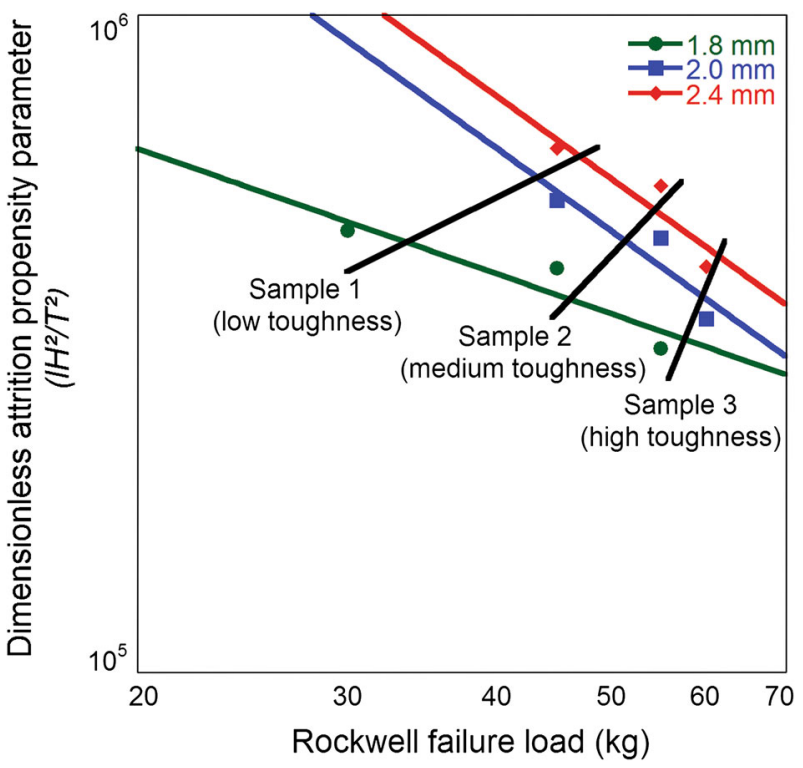

Fig. 6-Attrition propensity parameter vs Rockwell failure load. Low toughness polysilicon shows higher attrition compared to high toughness ones, and smaller granular shows lower attrition compared to larger ones.

granular as shown in Figure 8(a) has a ring structure morphology because of the porosity in the material. Figures 8(a) and (b) shows the distribution of the pores forming the rings, where our previous work measured the volume percent of the pores to range between 1 and 4 pct in polysilicon and their sizes ranges between 0.1 and $5 \mu \mathrm{m}$ in diameter. ${ }^{[19]}$

It was verified in our earlier studies that crack morphology in Vickers microindentation is not affected by fine porosity presented in the material ${ }^{[1]}$; this is also shown in Figure 2(a) where the cracks are not influenced by any of the pores presented in the sample. In this paper, we analyzed the effects of pores on fracture behavior on polysilicon under Rockwell applied load. Figure 9(a) shows the SEM image of a broken granular sample with the propagation of crack from the contact surface to the center with no influence from the pores. The crack 


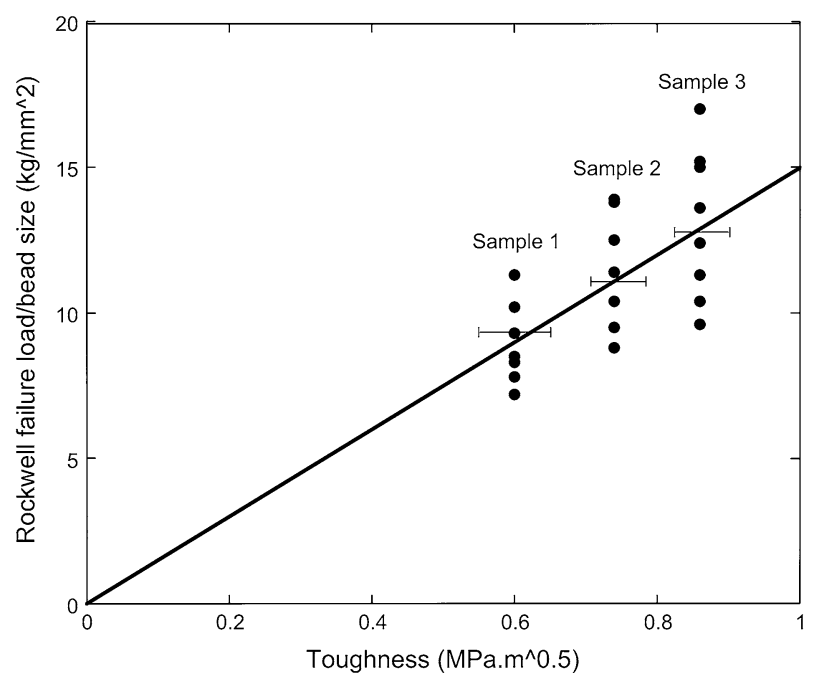

Fig. 7-Linear relationship between toughness and Rockwell failure load.
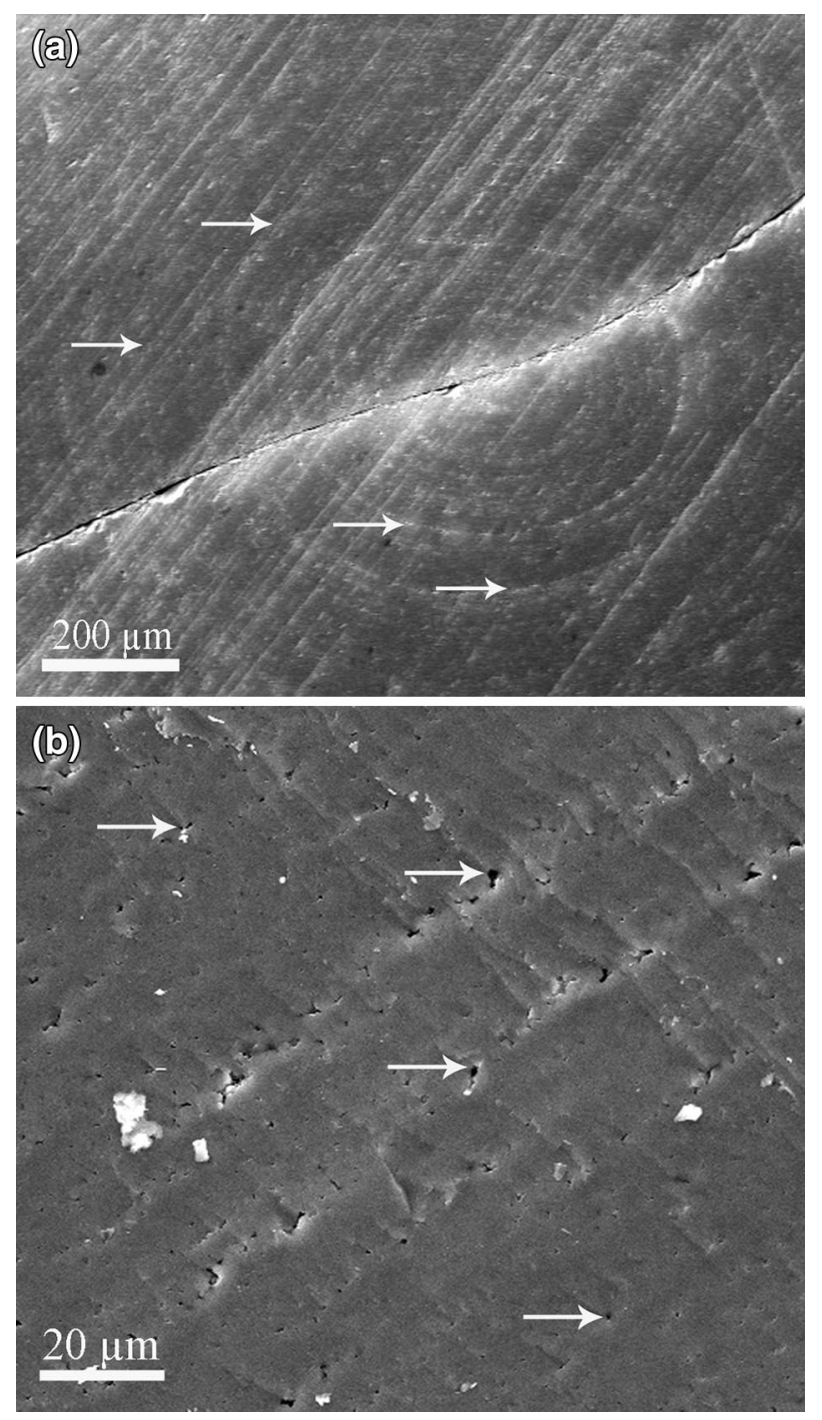

Fig. 8- SEM images showing rings structure of the formed pores (a) and distribution of pore sizes $(b)$; noted in arrows.
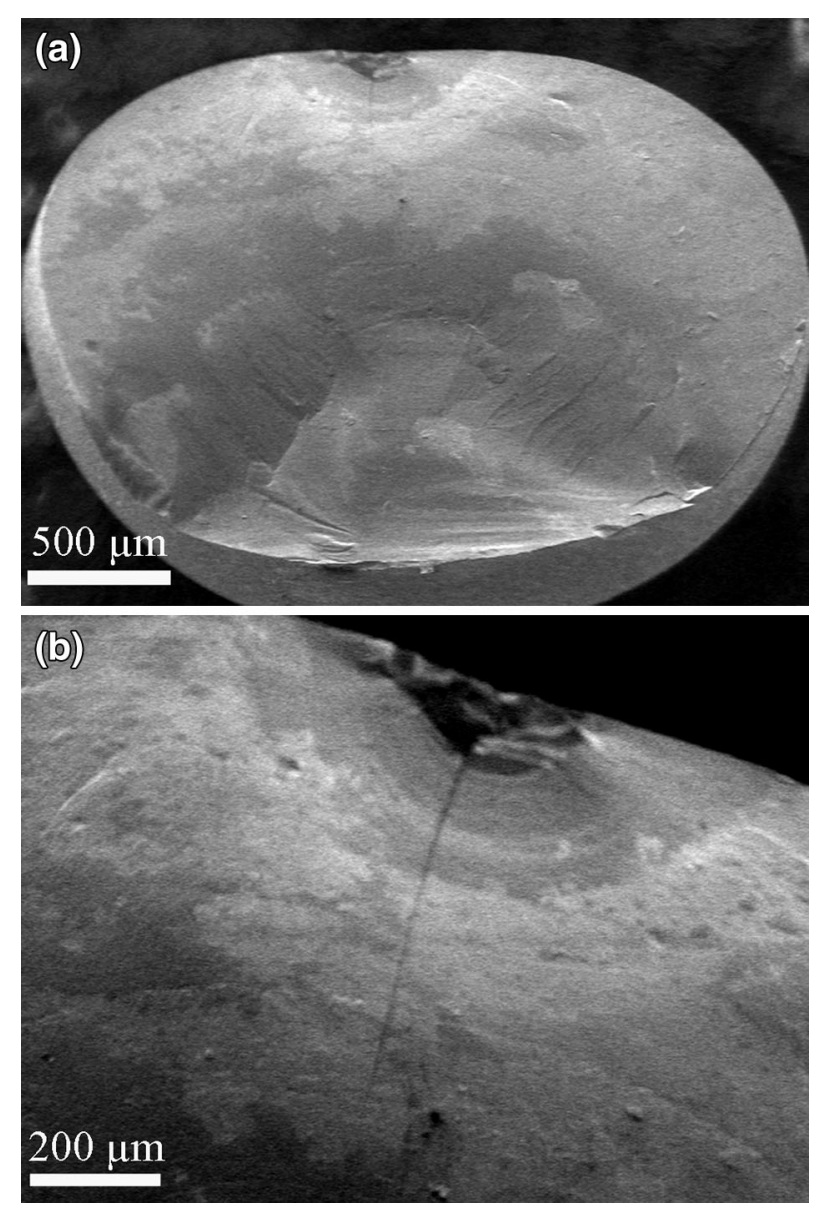

Fig. 9-SEM images of the fractured beads at the applied Rockwell failure load.

continues its path and does not show any significant deviations by any of the pores. Figure 9(b) with higher magnification shows the formation of rings along the pores with the propagation of the crack that passes through them without any changes in its morphology. This verifies that on both micro-scale and macro-scale load tests, there is no measureable influence of the pores on the fracture behavior of polysilicon.

\section{CONCLUSIONS}

The fracture behavior of granular polysilicon follows a similar trend when using a micro-scale (Vickers) and macro-scale (Rockwell) indentation techniques. Materials with low fracture toughness $\left(0.60 \mathrm{MPa} \mathrm{m}^{0.5}\right)$ were able to withstand up to $45 \mathrm{~kg}$ load, while materials with higher fracture toughness $\left(0.86 \mathrm{MPa} \mathrm{m}^{0.5}\right)$ withstood up to $60 \mathrm{~kg}$ load. All tested materials have same grain size, and, therefore, changes in toughness are ascribed solely to changes in solute $\mathrm{H}$ content. Porosity on the order of 1 to 4 pct does not influence the crack morphology on either the micro- or macro-scale tests. The use of a simple Rockwell hardness test is an efficient qualitative technique for the rapid assessment on the 
fracture behavior of polysilicon used as a precursor to solar cell silicon. Rockwell hardness testing equipment can be used to assess the failure behavior of polysilicon grown for the solar market via fluidized bed reactors by testing individual granules, with no need for any sample preparation. By simply applying different loads and observing the failure mechanism of the material, a correlation to the fracture toughness can be made, and an estimate of attrition behavior was determined. This method allows for rapid assessment and quality control of silicon granular products, and could be extended to other brittle granular materials.

\section{ACKNOWLEDGMENTS}

We would like to thank REC Silicon, Moses Lake WA, for the financial support of this research, and in particular Matthew Miller for his helpful discussions of the FBR process. Also, we thank MM Dahl for the images in Figure 8.

\section{REFERENCES}

1. M.B. Zbib, M.C. Tarun, M.G. Norton, D.F. Bahr, R. Nair, N.X Randall, and E.W. Osborne: J. Mater. Sci., 2010, vol. 45, pp. 1560-66.
2. M.M. Dahl, A. Bellou, D.F. Bahr, M.G. Norton, and E.W. Osborne: $J$ Cryst. Growth, 2009, vol. 311, pp. 1496-1500.

3. M.B. Zbib, M.G. Norton, and D.F. Bahr: Scripta Mater., 2012, vol. 67 , pp. $756-59$.

4. R.W. Fancher, C.M. Watkins, M.G. Norton, D.F. Bahr, and E.W. Osborne: J. Mater. Sci., 2001, vol. 36, pp. 5441-46.

5. C.F. St. John: Philos Mag., 1975, vol. 32, pp. 1193-1212.

6. M. Brede and P. Hansen: Acta Metall., 1988, vol. 36, pp. 2003-18.

7. P.B. Hirsch, J. Samuels, and S.G. Roberts: Proc. R. Soc. Lond. A, 1989, vol. 421, pp. 25-53.

8. C.P. Chen and M.H. Leipold: Am. Ceram. Soc. Bull., 1980, vol. 59, pp. 469-72.

9. A. George and G. Michot: Mater. Sci. Eng. A, 1993, vol. 164, pp. 118-34.

10. F. Ericson, S. Johansson, and J.A. Schweitz: Mater. Sci. Eng. A, 1988, vol. 105, pp. 131-41.

11. F. Ebrahimi and L. Kalwani: Mater. Sci. Eng. A, 1999, vol. 268, pp. 116-26.

12. C.R. Bemrose and J. Bridgwater: Powder Technol., 1987, vol. 49, pp. $97-126$.

13. M. Meier, E. John, D. Wieckhusen, W. Wirth, and W. Peukert: Powder Technol., 2009, vol. 188, pp. 301-13.

14. M. Ghadiria and Z. Zhang: Chem. Eng. Sci., 2002, vol. 57, pp. 3659-69.

15. Z. Zhang and M. Ghadiri: Chem. Eng. Sci., 2002, vol. 57, pp. 3671-86.

16. D.J. Morris and R.F. Cook: Int. J. Fract., 2005, vol. 136, pp. 23764.

17. W.C. Oliver and G.M. Pharr: J. Mater. Res., 1992, vol. 7, pp. 1564-83.

18. G.K. Williamson and W.H. Hall: Acta Metall., 1953, vol. 1, pp. $22-31$.

19. M.B. Zbib, M.M. Dahl, U. Sahaym, M.G. Norto, E.W. Osborne, and D.F. Bahr: J. Mater. Sci., 2012, vol. 47, pp. 2583-90. 